\title{
Bilateral Cryptophthalmus: First Case Report from Nepal
}

\author{
Nayana Pant ${ }^{1(\mathbb{2})}$, Subash Bhatta $^{(\mathbb{1}}$, Gulshan Bahadur Shrestha $^{2^{(\mathbb{D}}}$, Madhu Thapa $^{2^{(\mathbb{D}}}$ \\ ${ }^{1}$ Geta Eye Hospital, Dhangadhi, Nepal \\ ${ }^{2}$ BP Koirala Lions Center for Ophthalmic Studies, Institute of Medicine, Tribhuvan University, Kathmandu, Nepal
}

\begin{abstract}
Introduction: Cryptophthalmus is characterized by a partial or complete casing of the eyeball by the skin. Cryptophthalmus alongside other systemic abnormalities is well-known as Fraser syndrome. It is an unusual genetic disorder with limited literature. The complexities of disease and limited experience pose challenges in its management.

Case: A two-day-male neonate was brought by his parents with a complaint of swelling in the right orbital region and deformed left eye since birth. Examination revealed bilobed globular swelling in the right orbital region covered by a continuous sheet of skin from forehead to cheek with no visible ocular tissue. On the left side, there was absence of upper lid margin and eyelashes with superior symblepharon. He also had bilateral ear abnormalities and right renal agenesis. Surgical intervention was done. On the right side, removal of the globe and cyst was done. On the left side, upper eyelid reconstruction with symblepharon release was done with amniotic membrane transplantation.

Conclusions: The management of cryptophthalmus is challenging. Reconstructive surgeries allow cosmesis but useful vision is rarely gained. This is the first case report from Nepal to date to the best of our knowledge.
\end{abstract}

Key words: Amniotic membrane, Congenital symblepharon, Cryptophthalmus, Fraser syndrome.

\section{INTRODUCTION}

Cryptophthalmus is an unusual genetic ailment where we see eyes hidden by the continuous casing of skin from the forehead to the cheeks. Cryptophthalmus has three different ways of presentation as described by Francois (1969); complete (typical), incomplete (atypical) and abortive form(congenital symblepharonvariant). In complete form, there is an uninterrupted sheet of skin extending from forehead to cheeks

$\begin{array}{ll}\text { Financial Interest : Nil } & \text { Received : 18.01.2021 } \\ \text { Conflict of Interest : Nil } & \text { Accepted : 20.05.2021 } \\ \text { Corresponding Author } & \\ \text { Dr. Nayana Pant } & \\ \text { Geta Eye Hospital, } & \\ \text { Dhangadhi, Nepal } & \\ \text { E-mail: pantnayana@gmail.com } & \\ \text { Contact: +977 9841658991 }\end{array}$

Access this article online

Website: www.nepjol.info/index.php/NEPJOPH

DOI: https://doi.org/10.3126/nepjoph.v13i2.34372

Copyright $\odot 2021$ Nepal Ophthalmic Society ISSN: 2072-6805, E-ISSN: 2091-0320

This work is licensed under a Creative Commons

Attribution-NonCommercial-NoDerivatives 4.0 International License (CC BY-NC-ND). 
which hides the eyeball. In incomplete form, lids do exist but are undeveloped, and laterally, there is a small conjunctival sac. Globe is small and fully roofed with skin. In abortive form, there is a superior symblepharon. The superior lid is adhered with the superior part of the cornea causing an absence of superior conjunctival fornix. Globe is present, but the residual cornea is opaque or keratinized.

Fraser syndrome is a term used for cryptophthalmus in combination with other systemic abnormalities (Slavotinek et al, 2002). The prevalence of Fraser syndrome is 0.43 per 100,000 live births and 11.06 per 100,000 stillbirths as quoted by Martinez et al (1998). For diagnosing Fraser syndrome, diagnostic criteria have been set by Thomas et al (1986). Two major and one minor criterion or 1 major and four minor criteria from the following list must be present to label Fraser Syndrome.

Major criteria are:

1. Cryptophthalmus

2. Syndactyly

3. Abnormal genitalia

4. Siblings with Fraser syndrome

Minor criteria are:

1. Congenital malformation of Ear, Nose, Larynx

2. Cleft lip and / or palate

3. Skeletal defects

4. Umbilical hernia
5. Renal agenesis

6. Mental retardation

Surgical techniques for different types of cryptophthalmus are described in various literature and they have mentioned that surgical reconstruction and rehabilitation are difficult (Ding et al, 2017; Liu et al, 2019; Subramanian et al, 2013). Visual prognosis is guarded in complete cryptophthalmus, so surgery is done basically for cosmesis. In congenital symblepharon variant, some amount of functional vision can be provided to the patient but that too depends upon pre-existing ocular abnormality. This is the first case report of cryptophthalmus from Nepal to date to the best of our knowledge.

\section{CASE REPORT}

A two-day-male baby was brought by his parents from a village with complaints of an absence of right eye and swelling in the right orbital region along with deformed left eye since birth. The patient had no history of fever and trauma. The baby was feeding well with normal urine and stool habits. Antenatal history was uneventful. An anomaly scan was not done during pregnancy. Term baby was delivered at a local primary health facility with a birth weight of 3.5 $\mathrm{kg}$ by spontaneous vaginal delivery. The baby was born to a mother of 21 years and father of 23 years old. There was no history of consanguinity in the family. On general physical examination, the baby looked playful with a weight of $3.7 \mathrm{~kg}$. Vitals were stable. Congenital malformation 

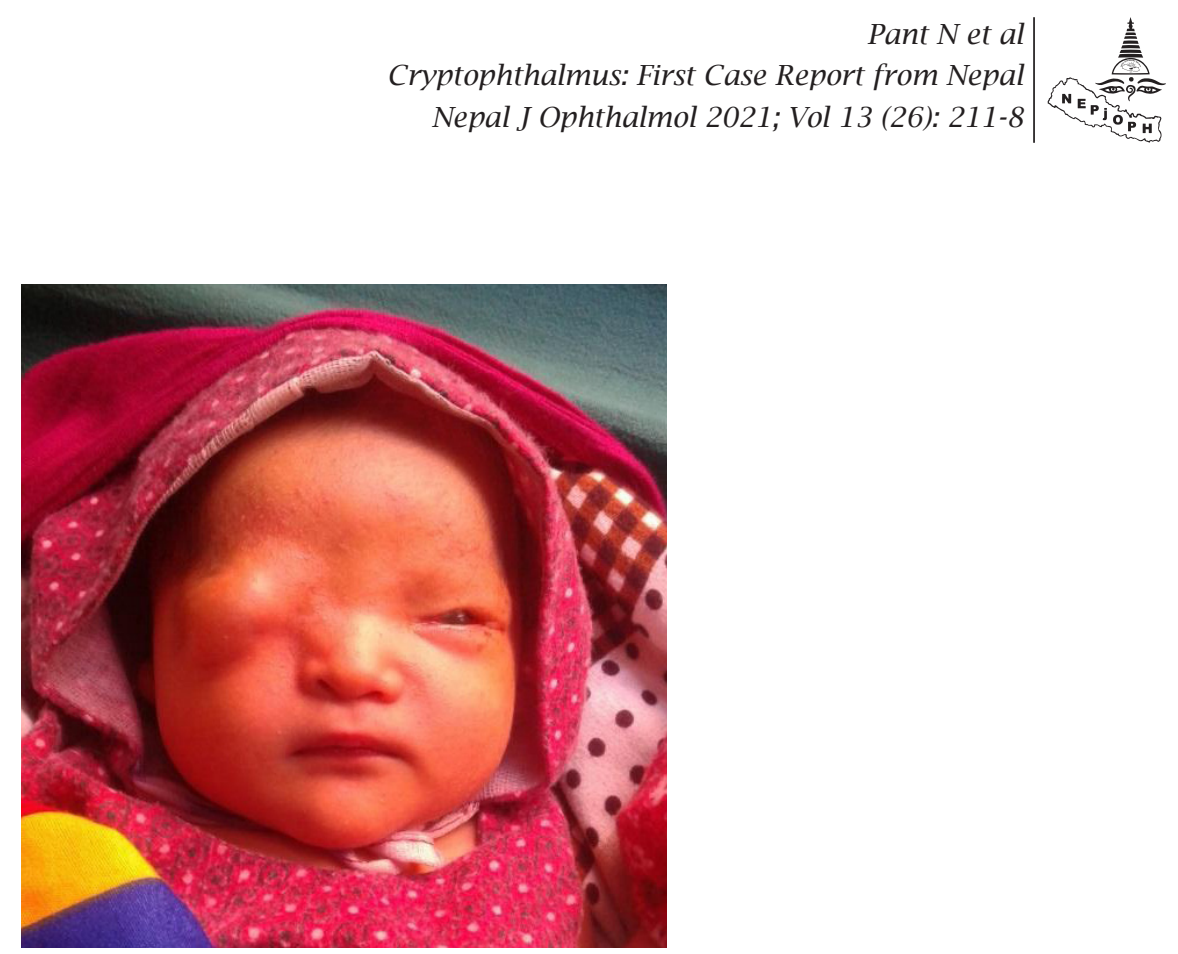

Figure 1: Swelling in the right orbital region, left sided superior symblepharon.
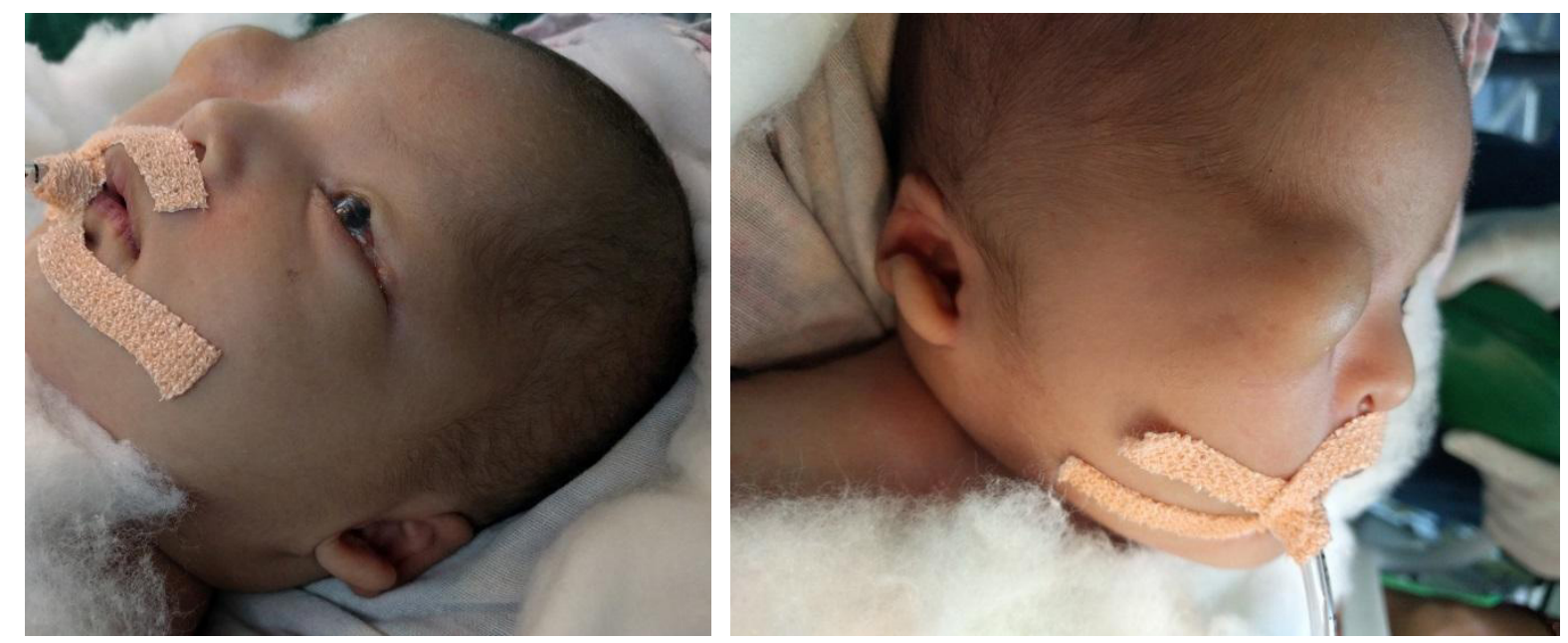

Figure 2 and 3: Right and left ear abnormalities.

was seen in the right globe and left upper eyelid and both ears (Figure 1, 2 and 3). On systemic examination, there was no musculoskeletal deformity, testes were descended and abnormal genitalia was not seen. On ocular examination, there was a continuous sheet of skin extending from forehead to cheek on the right side. The ocular tissue was unidentifiable. There was bilobed globular swelling in the right orbital region with normal skin on the surface with no color changes. On examination of the left eyelid, there was an absence of upper lid margin and lashes. The upper eyelid was adherent to the superior one-third of the cornea (superior symblepharon) and there was the loss of corneal lustre (Figure 4). A provisional diagnosis of right-sided cryptophthalmus and left-sided congenital symblepharon variant was made. The patient was admitted and investigations were done. Blood investigations revealed normal 
\begin{tabular}{l|l} 
Cant N et al \\
Cryptophthalmus: First Case Report from Nepal \\
Nepal J Ophthalmol 2021; Vol 13 (26): 211-8
\end{tabular}

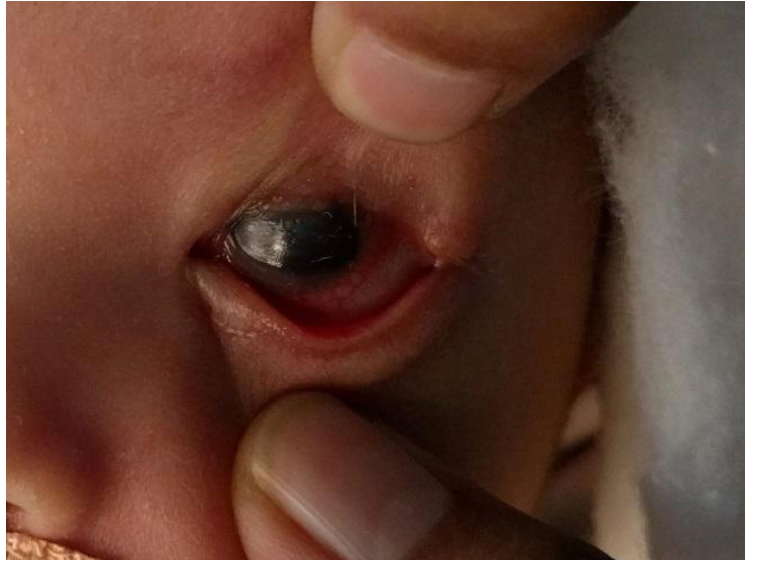

Figure 4: Superior symblepharon with loss of corneal lustre.

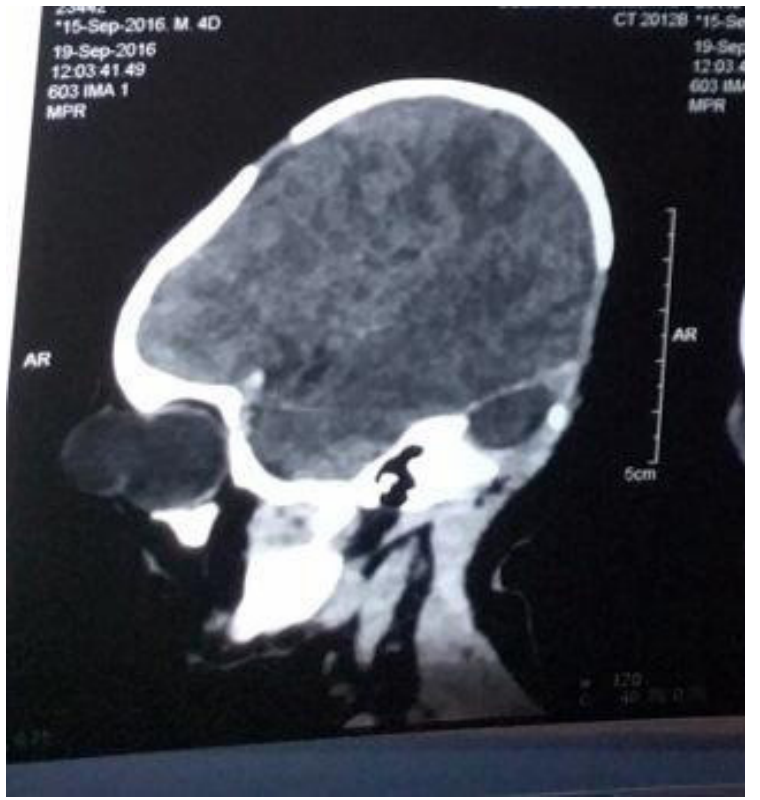

Figure 6: CT scan head and orbit (Sagittal view): Right deformed, enlarged bilobed globe with proptosis.

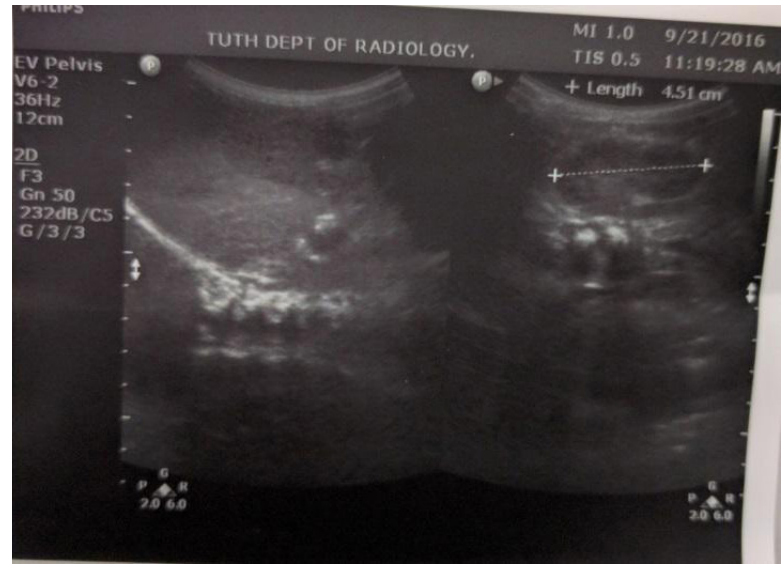

Figure 5: Ultrasonogram of abdomen showing renal agenesis on the right side.

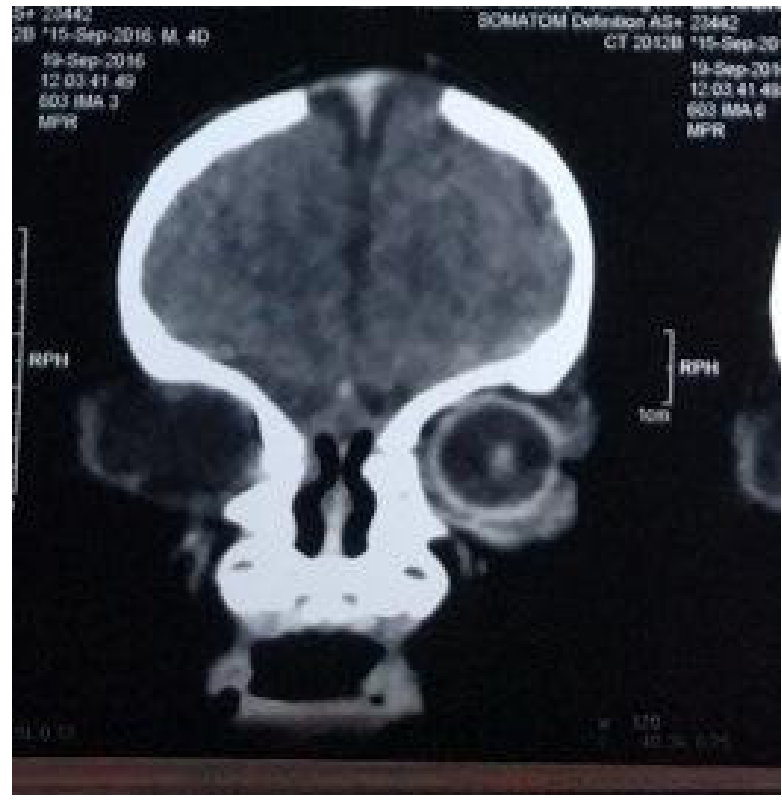

Figure 7: CT scan head and orbit (Coronal view): Normal left globe and orbit. findings. An Infantogram, ultrasonography of the abdomen and pelvis was done to rule out any musculoskeletal and urogenital abnormalities. Infantogram was normal. Ultrasonogram of abdomen and pelvis revealed right-sided renal agenesis (Figure 5). CT scan of the head and orbit showed a deformed and enlarged bilobed right globe with a disorganized anterior chamber and no evidence of lens (Figure 6). The left side globe was normal (Figure 7). The baby was operated on the 16th day of life. Upper eyelid reconstruction and symblepharon release with 

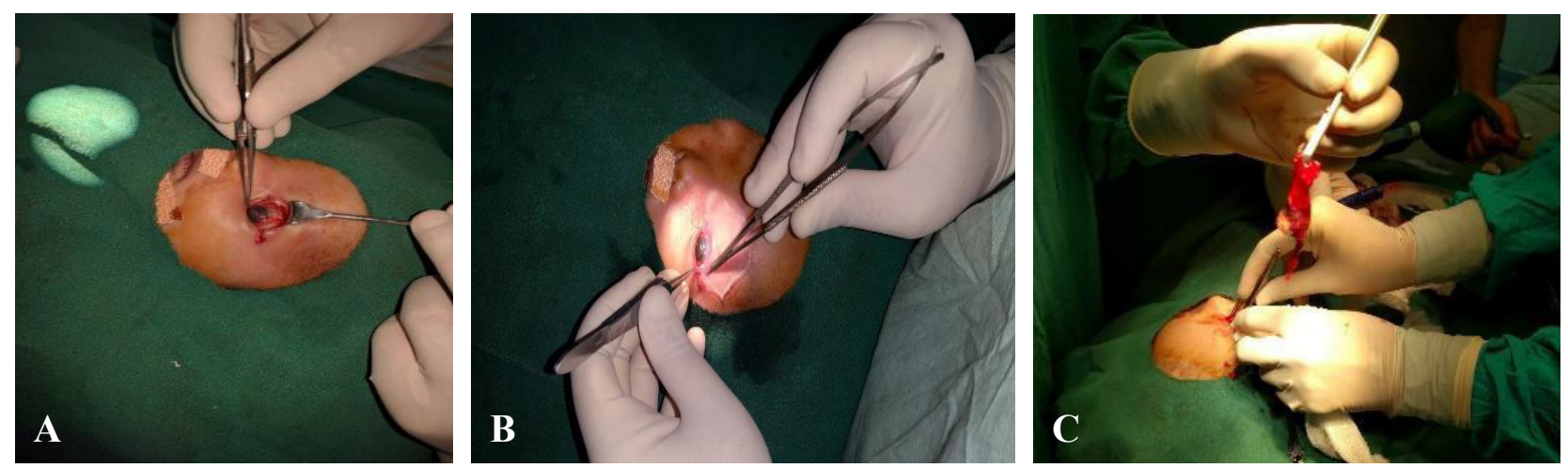

Figure 8: Steps of surgery (A: Symblepharon released, B: Amniotic membrane transplant done, $C$ : Removal of globe and cyst).

Figure A, B - left eye; Figure C-right eye.

amniotic membrane transplantation were done in the left eye (Figure 8A). There was a defect in the margin of the left upper eyelid. The superior rectus muscle was intact. Amniotic membrane was grafted over the bare area and sutured to the superior limbus and remnants of superior bulbar conjunctiva (Figure 9B). Anterior lamella of the eyelid was formed by mobilizing pre-existing lid tissue and posterior lamella was constructed with an amniotic membrane. Fornix was formed and central temporary tarsorrhaphy was done. On the right side, removal of the globe and cyst was done. The skin incision was made over the swelling, soft tissue dissection was done and an anomalous globe with cyst was separated from surrounding soft tissue (Figure 8C and 9). During the dissection, fluid and vitreous-like jelly were seen as the cyst ruptured. The skin was closed. The tissue was sent for histopathology. As the child was only 15 days old and malignancy was not ruled out, orbital rehabilitation was planned for the future. Histopathology reports of the tissue revealed microphthalmia with a cyst. Lens and cornea were not identified. Retina and choroid showed a regular arrangement of cells. Optic nerve was seen. No malignant cells were identified.

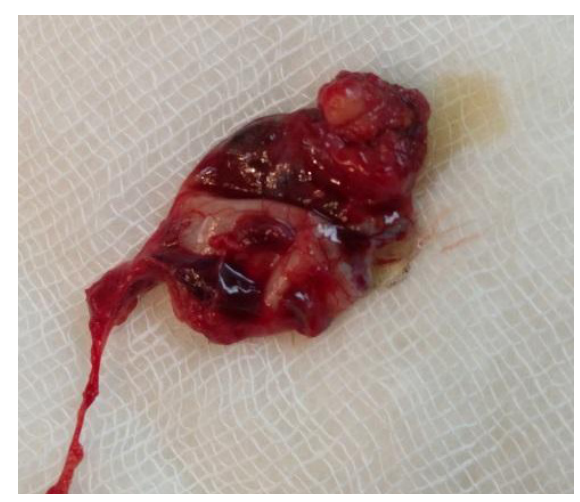

Figure 9: Specimen of the right globe and cyst. 


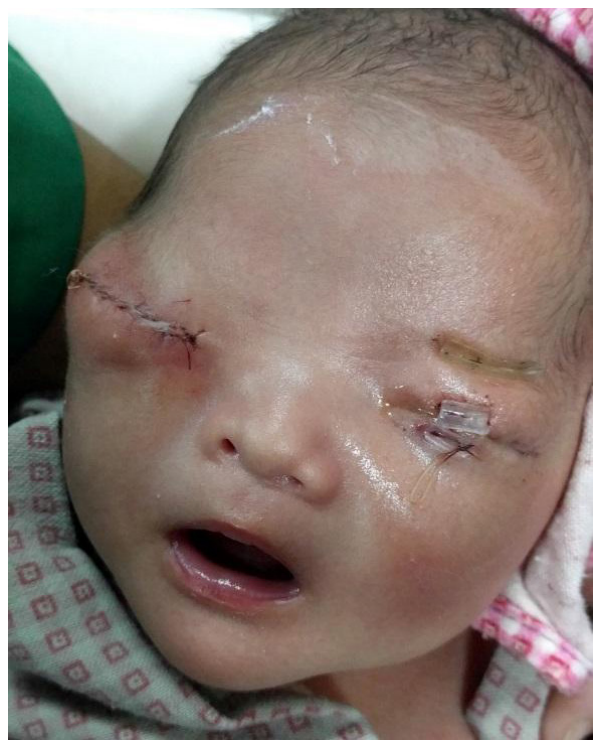

Figure 10: First postoperative day: Swelling on both sides.

The swelling was present in an immediate postoperative period which subsided later (Figure 10). Tarsorrhaphy was released after 5 days. On follow-up, the patient had improved cosmesis (Figure 11). Further staged surgeries are required for full cosmesis. The functional outcome needs to be monitored in the follow-up visits.

\section{DISCUSSION}

Cryptophthalmus is an unusual inherited ailment which occurs due to atypical lid fold development in an embryo. In this case report, we describe a two-day male with right-sided complete cryptophthalmus and left-sided congenital symblepharon variant with surgical management. Frequently, cryptophthalmus is seen to occur alongside additional systemic abnormalities in Fraser syndrome (Slavotinek

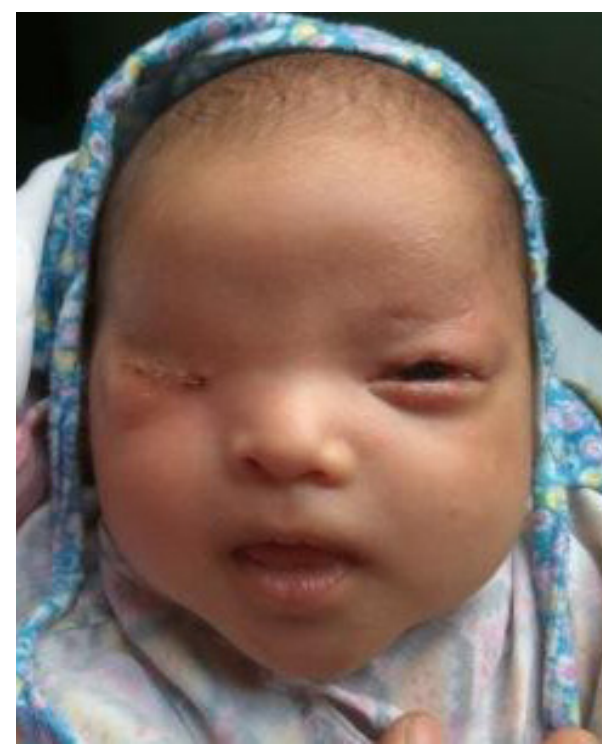

Figure 11: 20th postoperative day. et al, 2002). In this particular case, the baby had complete cryptophthalmus on the right side, congenital symblepharon variant on the left side. The patient did not have syndactyly in any of the limbs. Genital examination was normal. Patient is the first child of parents and there is no history of abortion in the mother, so there was no history of similar illness in siblings. Thus, only one point from major criteria is present in the patient. Talking about minor criteria, there is presence of malformation of both ears on examination. The baby has rightsided renal agenesis which was detected on ultrasonogram. There was no cleft lip and palate and no umbilical hernia. Infantogram did not reveal any skeletal abnormalities. The patient could not be assessed for mental retardation since he was a new-born. Therefore, the patient had two points from minor criteria. Having one point from major criteria and only two points 
Table 1: Criteria for diagnosis of Fraser syndrome and criteria present in this case report.

\begin{tabular}{|l|l|l|l|}
\hline \multicolumn{1}{|c|}{ Major Criteria (4) } & Case Report (1) & \multicolumn{1}{c|}{ Minor Criteria (6) } & Case Report (2) \\
\hline Cryptophthalmus & Present & $\begin{array}{l}\text { Congenital malformation } \\
\text { of Ear, Nose, Larynx }\end{array}$ & Present \\
\hline Syndactyly & & Cleft lip and / or palate & \\
\hline Abnormal genitalia & & Skeletal defects & \\
\hline Siblings with Fraser syndrome & & Umbilical hernia & \\
\hline & & Renal agenesis & Present \\
\hline \multicolumn{2}{|l|}{ Mental retardation } & \\
\hline Diagnosis of Fraser Syndrome: 2 major+1 minor or, 1 major+4 minor criteria \\
\hline
\end{tabular}

from minor criteria, the baby did not fulfil the criteria of Fraser syndrome as shown in Table 1.

Therefore, diagnosis of cryptophthalmus associated with systemic abnormalities was made.Incryptophthalmus, prenatalidentification can be done with the help of ultrasonography by inspecting eyes, digits, kidney, and lungs in utero (Fryns et al, 1997, Schauer et al, 1990). The risk of acquiring this disease in siblings is reported to be about 25\% (Ramsing et al, 1990). Thus genetic counselling is a must and anomaly scan is necessary in all successive children. So, appropriate counselling was provided to the parents for planning their next baby. Early surgical intervention is important and most of the time staged procedures may be required. Surgical management is more of cosmetic value but can provide vision in few cases. In this patient, right sided excisional biopsy was done to rule out malignancy. The specimen showed choroid, retina and sclera but lens and cornea were not identified and malignant cells were not seen. Another staged surgery is required in the right side for orbital reconstruction and prosthetic orbital implant. In the left eye, symblepharon release and upper eyelid reconstruction with amniotic membrane graft were done. With surgery, better cosmesis could be given to the patient.

\section{CONCLUSION}

Cryptophthalmus is a rare genetic disease. The management of cryptophthalmus is challenging. Reconstructive surgeries allow cosmesis but useful vision is rarely gained. A rare case of cryptophthalmus associated with systemic anomalies has been reported for the first time from Nepal.

Limitation of the study: Genetic study could not be done.

Acknowledgement: Authors would like to acknowledge Dr. Vivek Pant for his continuous support in preparation of this case report.

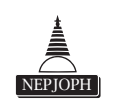




\section{REFERENCES}

Ding J, Hou Z, Li Y, Lu N, Li D (2017). Eyelid and fornix reconstruction in abortive cryptophthalmus: a single-center experience over 12 years. Eye (Lond);3:1576-81. doi: 10.1038/eye.2017.94; PMid:28622309

Francois J (1969). Syndrome malformatif avec cryptophtalmie. Acta Genet Med Gemellol (Roma);18(1):18-50. doi: 10.1017/S1120962300012294; PMid:5799332

Fryns J. P, Van Schoubroeck D, Vandenberghe K, Nagels H, Klerckx P (1997). Diagnostic echographic findings in cryptophthalmus syndrome (Fraser syndrome). Prenatal Diagnosis: Published in Affiliation With the International Society for Prenatal Diagnosis;17(6):582-4. doi: 10.1002/(SICI)1097-0223(199706)17:6<582::AIDPD107>3.0.CO;2-Y

Liu Z, Xie B, Li Y, Ding J, Li D (2019). Reconstruction strategy in isolated complete Cryptophthalmus: a case series. BMC ophthalmology;19(1):165. doi: 10.1186/s12886-019-1170-6; PMid:31366340

Martinez-Frias ML, Bermejo ES, Felix V, Calvo RC, Ayala AG, Hernández FR (1998). Fraser syndrome: frequency in our environment and clinical epidemiological aspects of a consecutive series of cases. Anales espanoles de pediatria;48(6):634-8.

Ramsing M, Rehder H, Holzgreve W, Meinecke P, Lenz W (1990). Fraser syndrome (cryptophthalmus with syndactyly) in the fetus and newborn. Clin Genet.;37:84-96. doi: 10.1111/j.1399-0004.1990.tb03484.x; PMid:2155726

Schauer GM, Dunn LK, Godmilow L, Eagle Jr RC, Knisely AS (1990). Prenatal diagnosis of Fraser syndrome at 18.5 weeks gestation, with autopsy findings at 19 weeks. American Journal of Medical Genetics. 37(4):583-91. doi: 10.1002/ajmg.1320370433; PMid:2175543

Slavotinek AM, Tifft CJ (2002). Fraser syndrome and cryptophthalmus: Review of the diagnostic criteria and evidence for phenotypic modules in complex malformation syndromes. J Med Genet;39:623-33. doi: 10.1136/jmg.39.9.623; PMid:12205104

Subramanian N, Iyer G, Srinivasan B (2013). Cryptophthalmus: Reconstructive Techniques-Expanded Classification of Congenital Symblepharon Variant. Ophthalmic Plastic and Reconstructive Surgery;29(4):243-8. doi: 10.1097/ IOP.0b013e3182895683; PMid:23619465

Thomas IT, Frias L, Felix V, Sanchez de Leon L, Hernandez RA, Jones MC, et al. Isolated and syndromic cryptophthalmus (1986). American Journal of Medical Genetics;25(1):85-98. doi: 10.1002/ajmg.1320250111 